\title{
Effects of environmental change on emerging parasitic diseases
}

\author{
Jonathan A. Patz ${ }^{\mathrm{a}, *}$, Thaddeus K. Graczyk ${ }^{\mathrm{b}}$, Nina Geller ${ }^{\mathrm{a}}$, Amy Y. Vittor ${ }^{\mathrm{c}}$ \\ ${ }^{\mathrm{a}}$ Department of Environmental Health Sciences, Johns Hopkins University School of Hygiene and Public Health, 615 N. Wolfe Street, Baltimore, \\ MD 21205-2179, USA. \\ ${ }^{\mathrm{b}}$ Department of Molecular Microbiology and Immunology, Johns Hopkins University School of Hygiene and Public Health, 615 N. Wolfe Street, Baltimore, \\ MD 21205-2179, USA \\ ${ }^{\mathrm{c} D e p a r t m e n t ~ o f ~ I n t e r n a t i o n a l ~ H e a l t h, ~ J o h n s ~ H o p k i n s ~ U n i v e r s i t y ~ S c h o o l ~ o f ~ H y g i e n e ~ a n d ~ P u b l i c ~ H e a l t h, ~} 615$ N. Wolfe Street, Baltimore, MD 21205-2179, USA
}

Received 18 September 2000; received in revised form 19 September 2000; accepted 19 September 2000

\begin{abstract}
Ecological disturbances exert an influence on the emergence and proliferation of malaria and zoonotic parasitic diseases, including, Leishmaniasis, cryptosporidiosis, giardiasis, trypanosomiasis, schistosomiasis, filariasis, onchocerciasis, and loiasis. Each environmental change, whether occurring as a natural phenomenon or through human intervention, changes the ecological balance and context within which disease hosts or vectors and parasites breed, develop, and transmit disease. Each species occupies a particular ecological niche and vector species sub-populations are distinct behaviourally and genetically as they adapt to man-made environments. Most zoonotic parasites display three distinct life cycles: sylvatic, zoonotic, and anthroponotic. In adapting to changed environmental conditions, including reduced nonhuman population and increased human population, some vectors display conversion from a primarily zoophyllic to primarily anthrophyllic orientation. Deforestation and ensuing changes in landuse, human settlement, commercial development, road construction, water control systems (dams, canals, irrigation systems, reservoirs), and climate, singly, and in combination have been accompanied by global increases in morbidity and mortality from emergent parasitic disease. The replacement of forests with crop farming, ranching, and raising small animals can create supportive habitats for parasites and their host vectors. When the landuse of deforested areas changes, the pattern of human settlement is altered and habitat fragmentation may provide opportunities for exchange and transmission of parasites to the heretofore uninfected humans. Construction of water control projects can lead to shifts in such vector populations as snails and mosquitoes and their parasites. Construction of roads in previously inaccessible forested areas can lead to erosion, and stagnant ponds by blocking the flow of streams when the water rises during the rainy season. The combined effects of environmentally detrimental changes in local landuse and alterations in global climate disrupt the natural ecosystem and can increase the risk of transmission of parasitic diseases to the human population. (C) 2000 Australian Society for Parasitology Inc. Published by Elsevier Science Ltd. All rights reserved.
\end{abstract}

Keywords: Biodiversity; Cryptosporidiosis; Deforestation; El Niño; Global warning; Landuse

\section{Introduction}

Environmental changes and ecological disturbances, due to both natural phenomena and human intervention, have exerted and can be expected to continue to exert a marked influence on the emergence and proliferation of zoonotic parasitic diseases.

The first section of this article presents the types of environmental conditions and changes that contribute to proliferation of emerging parasitic diseases. The effects of changes in landuse, especially deforestation and its sequelae, water control projects, road construction, and climatic changes on vectors and their parasites are discussed.

The second section focuses on malaria and the zoonotic

\footnotetext{
* Corresponding author. Tel.: +1-410-955-4195; fax: +1-410-955-1811.

E-mail address: jpatz@jhsph.edu (J.A. Patz).
}

parasitic diseases most commonly affected by environmental changes and which constitute the greatest threats to human populations. The effects of ecological disruption on each of the diseases are discussed within the context of their local environments.

\section{Environmental changes affecting transmission of zoonotic parasitic diseases}

Each environmental change natural phenomenon or through human intervention, alters the ecological balance and context within which vectors and their parasites breed, develop, and transmit disease. The mix of vectors, their biodiversity, abundance, vector competence and human biting behaviour can be affected by any one of the multifactoral changes occurring as ecological stability is 
disrupted. Deforestation and ensuing changes in landuse, human settlement, commercial development, construction of roads, water control systems (dams, canals, irrigation systems, reservoirs), and climate singly and in combination have been accompanied by global increases in morbidity and mortality from a number of emergent parasitic diseases.

The nature and extent of change in the incidence of parasitic disease are affected by changes in landuse and settlement, the time interval from one landuse to another/others, changes in type of soil and its degree of water absorption, changes in vegetation characteristics, changes in the types and amounts of bodies of water, their size, shape, temperature, $\mathrm{pH}$, flow, movement, sedimentation and proximity to vegetation and, changes in climate. All affect parasite and insect vectors, and in turn, the incidence and prevalence of parasitic disease.

\subsection{Deforestation}

Deforestation is one of the most disruptive changes affecting parasitic vector populations. When the forest is cleared and erosion of the soil strips away the thin layer of nutrients, it may take up to 50 years or more before the area resembles its former state, if indeed, it is permitted and able to regenerate. The response of tropical forests to pertubation is affected by soil type, elevation, mean precipitation, and latitude. Cleared tropical forests are typically converted into grazing land for cattle, small-scale agricultural plots, human settlements or, left as open areas. Expansion of existing human settlements and movement of human populations create a need for increased food supply, leading to changes in the types and amounts of vegetation, thereby providing changed ecological niches and conditions for proliferation of newly arriving and/ or adaptive existing vectors and their parasites.

\subsection{Replacement of forests with crop farming, ranching, small animals}

The replacement of forests with crop farming, ranching, and raising small animals can create a supportive habitat for parasites and their host vectors. Introduction of new to-thearea animal species, such as cattle, pigs, and chickens can result, variously, in either increased or decreased transmission of parasitic disease to humans [1].

With livestock to feed up on, the vectors may reduce feeding on humans or, conversely, with the plethora of livestock blood resources, vectors may multiply and seek additional, that is, human, feed sources [2]. With the larger reservoirs of infection, there is increased parasite transmission and, the humans not only become ill, but also further increase the parasite reservoirs.

\subsection{Bodies of water in disrupted areas}

Soil type and elevation contribute to determining the type of bodies of water formed in disrupted areas. Whereas the forest floor in primary growth tends to be heavily shaded and littered with a thick layer of organic matter that absorbs water and renders it quite acidic ( $\mathrm{pH} 4.5-5.5)$, cleared lands are generally more sunlit and prone to the formation of puddles with more neutral $\mathrm{pH}$ [3-5] which can favour specific anopheline larvae development (described below). Puddles with clear water $(\mathrm{H}<5.5)$ form in sandy soils when the soil is saturated, and muddy puddles $(\mathrm{pH}>5.5)$ form in areas with red clay [6]. Reduction in water salinity and conversion from acidic to alkaline condition increase fecundity and growth of freshwater vectors such as snails, enhancing the transmission of their parasite [7]. Terrain affects the manner in which water collects in deforested areas: on steep inclines, streams are more common than large pools. Crops such as sugar cane or rice may be surrounded by a network of irrigation ditches and artificial bodies of water may be formed for small fish farms and wells.

\subsection{Human movement}

When deforested areas are replaced by crop agriculture, the pattern of human settlement usually changes. In addition to an influx of settlers, migrants may come, and if a suitable anthrophyllic vector is present, the migrants become a reservoir for transmission of parasitic disease endemic to their former home grounds, but foreign to the non-immune resident settlers. Indigenous forest dwellers generally have developed immunity to forest-dwelling parasites. However, during the process of deforestation, as the forest recedes, new settlers who are drawn to the edge of the forest for agricultural activities, or enter the remaining forest for commercial activity such as logging, are particularly vulnerable as they lack immunity to the zoonotic parasitic diseases endemic to the area.

The new settlement is frequently environmentally different from the settlers' previous home areas and populated with unfamiliar vectors and parasites to which they have not developed protective immunity. They may well lack familiarity with self-protective habits that would limit their availability as feed sources to vectors, e.g. using bed nets and remaining indoors during peak biting hours. Their resulting increased vulnerability to resident vectors can serve as the kindling for an outbreak of disease.

During the processes of landscape fragmentation and urbanization, both animals and humans are exposed to new contacts in new environments. As human settlements move from sparsely settled, formerly forested areas to more densely populated deforested areas with parasite dense human reservoirs for vectors to feed upon and increased interactions, the opportunities for exchange and transmission of parasites increase.

\subsection{Vector competence}

Levels of vector competence vary among species. As the ecology of an area changes, for example, becomes deforested, so too, there are changes of the species in the area. Each species occupies a particular ecological niche and sub- 
populations of vector species are distinct behaviourally, with differences by geographic region and in frequency of chromosomal inversion, suggesting population adaptation to man-made environments [8]. The human biting behaviour of vectors are affected by human availability, flight range of the vector, its biting frequency, and biting times in relation to human habits.

The degree of a parasite's genetic diversity may also vary among endemic geographic regions, and is related to the intensity of disease transmission [9-12].

\subsection{Zoophyllic to anthrophyllic orientation}

In adapting to changed environmental conditions, including reduction of non-human population and increased human population, some vectors display a conversion from a primarily zoophyllic to primarily anthrophyllic orientation. Most zoonotic parasites display three distinctive life cycles: sylvatic, zoonotic, and anthroponotic [13-16]. The parasite eradicated from human and domestic animal populations, for example, through anthelmintic programs, can survive in sylvatic habitats of national parks or wildlife refuges and then, subsequently, re-invade human and domestic animal reservoirs $[13,15,16]$. This interchange is exacerbated by most of the animal conservation operations being localised in developing or underdeveloped countries where public health policies are not well executed, sanitation standards are not aggressively enforced, and disease control activities are often inadequate or unavailable [17]

\subsection{Water control projects}

Reservoirs, irrigation canals, and dams are closely associated with parasitic disease. Construction of reservoirs and canals can lead to a shift in vector populations, such as snails and mosquitoes, their larvae and their parasites. In the tropics, during construction of dams and canals, excavation pits provide breeding sites for mosquitoes where they lay buoyant egg masses. Tropical reservoirs and irrigation systems provide ideal aquaria for rapid reproduction and growth of fluke-transmitting aquatic snails. Additional breeding sites are provided by creation of basin irrigation for rice, by poor drainage, and impounded water and seepage. The larvae, having no air tube, float just beneath the water's surface.

Different mosquito species vary in their habitat requirements, in both the larval and adult stages. Some species prefer sunlit pools with turbid water, with little or no emergent vegetation. Some larvae prefer clear water, inhabiting the edges of clean, clear, gently moving streams or, conversely, others thrive in irrigation and hydroelectric reservoirs with their frequent changes in water level, vertical shorelines, and emergent vegetation without organic material or salinity; others inhabit coastal areas with high salinity. There are species which require extensive vegetation cover and inhabit swamps and relatively permanent waterbodies with organic material.
Riverine pools, created by diversion of flow out of river beds, provide breeding in shallow, stagnant surface water exposed to sunlight. Deeply shaded pools, seepages in forests, footprints, mining pits and irrigation ditches, and excavated depressions in the open sunlight all provide areas for mosquitoes to deposit their eggs [18]. Unfortunately, the wide variety of conditions under which at least a few species are able to thrive ensures that parasitic disease is ubiquitous, flourishing throughout many regions of the world, especially in tropical areas.

\subsection{Road construction}

The construction of new roads provides access for new human, livestock, vector and parasite populations. Roads facilitate acceleration of crop farming, ranching, logging, mining, commercial development, tourism and, building of dams and hydroelectric plants and new settlements, with all their attendant disruption of the ecological balance.

Construction of roads in previously inaccessible forested areas can lead to erosion [19] and may create ponds by blocking the flow of streams when the water rises during the rainy season. The ponds then serve as breeding grounds. By providing access to forested and newly deforested areas, non-immune, non-protected populations, such as construction workers, loggers, miners, tourists and conservationists, are exposed to indigenous and newly arrived vectors and their parasites. Further, these visiting human populations bring with them and introduce to existing vectors and settlers along the forested/deforested interface, parasitic infections, and new vector species from their far flung points origin. Establishment of animal conservation and rehabilitation centres, national parks and wildlife reserves, which is facilitated by new access roads, increases the association between humans and animals [20-23], as do zoos, aquaria, and seaworlds [24-28], industrial animal production, nontraditional agriculture [21,29,30], aquaculture [31], freeranging/farmed game species and hunting [13,32,33,34].

\subsection{Climate and parasitic disease}

Climate is usually defined as the average weather, (i.e. short term - hours to days - fluctuation), over a period of years and in a particular geographic region. Climate involves variations in interactions among different components of the climate system: the atmosphere, the oceans, sea ice, and land features. Changes in any of the climate system components, whether internal or from external forcings, can cause climatic variation and change. The aggregate effect of temperature, precipitation, humidity, solar radiation and wind which are reflected in the type of vegetation in plant communities contribute to determining the nature of vector populations [35].

In earlier times, changes in climate occurred solely through natural processes resulting from phenomena such as changes in the output of the sun or slowing of ocean circulation. Today, human activities also contribute to 
climate change: fossil-fuel combustion (coal, oil, and gas) increasing the concentration of $\mathrm{CO}_{2}$; deforestation reducing $\mathrm{CO}_{2}$, absorbing capacity of forested areas; industrial activity and biomass burning resulting in emissions of gases such as carbon monoxide (CO) and volatile organic compounds (e.g. butane, propane) that undergo photo-oxidation in the presence of nitrogen oxides to form tropospheric ozone; doubling of atmospheric methane $\left(\mathrm{CH}_{4}\right)$ from pre-industrial levels [36] with current levels at the highest ever [37]. Halogenated compounds that do not exist naturally are now present in substantial amounts in the atmosphere, and have high greenhouse warming properties, in addition to their destructive effect on the stratospheric ozone layer [38].

Small changes in the mean climate can produce relatively large changes in the frequency of extreme weather events and frequency and severity of heat waves, [39]. Warmer temperatures are expected to lead to a more vigorous hydrological cycle, causing increased precipitation intensity and more rainfall events. However, ironically, higher mean temperatures may also lead to reduced soil moisture due to enhanced evaporation [40].

\subsection{Temperature and rainfall}

During the twentieth century, there was a rise in average daily temperatures; during the last fifty years, surface temperatures appear to have been warmer than any similar period in the last 600 years. [41]. And, because warmer air can hold more moisture than cooler air, the hydrologic cycle has changed, particularly affecting waterborne disease vectors, which are sensitive to changes in the hydrological cycles. There were also increases in cloud cover [42], total precipitation [43], and frequency in extreme precipitation events, at an intensity of more than two inches per day [4446]. It is expected that by the year 2100 , there will be a $2^{\circ} \mathrm{C}$ rise in temperatures with accompanying indirect effects: a $49 \mathrm{~cm}$. rise in sea level, an increase in hydrologic extremes [38] and enhanced evaporation, leading to both more droughts and more floods, and prolonged recovery of the ozone hole [47]. Extreme weather has deleterious effects on the population: drought resulting in poor hygiene and reduced food supplies, floods in contamination. Although global distribution of these changes are expected to be unequal, they are expected to result in significant wideranging effect on ecosystems [48].

As global warming continues, there is concern for increased transmission of same tropical diseases and potential for their expansion (of debatable extent) [52] into temperate regions [49-51]. For example, temperature determines the rate at which mosquitoes develop into adults, the frequency of their blood feeding, the rate with which parasites are acquired and, the incubation time of the parasite within the mosquito. These influences must be compared with the opposing effects that high temperatures exert in reducing adult mosquito survival.

Altitude can serve as a proxy for temperature; the average temperature decrease with height is $100 \mathrm{~m}$ in free atmosphere [53]. Recent mathematical simulations, using, as an example, the minimum temperatures of approximately 18 and $15^{\circ} \mathrm{C}$ for the development of the malaria parasites, Plasmodium falciparum and $P$. vivax, respectively, calculated the altitudes (which vary by latitude) at which these temperatures occur. With a threshold temperature of greater than $20^{\circ} \mathrm{C}$ required to spark an epidemic [54], areas in Africa above 1000-1500 $\mathrm{m}$ are considered safe from the spread of malaria.

Rainfall intensity is considered a key determinant of the transport of pathogenic micro-organisms, including parasites. During periods of heavy rainfall or melting snow, when the capacity of a sewer system and/or treatment plant can be overwhelmed, the excess wastewater may be discharged directly into surface water bodies $[55,56]$.

The length of rainy and dry seasons and the interval between seasons affects larvae and adult vector development and abundance. Transmission of many parasitic diseases is confined to the rainy season. Rain provides the breeding sites for mosquitoes and helps create a humid environment, which prolongs the life of vectors. The distribution of snails and their Schistoma parasite species are also sensitive to the amount of rainfall and length of the dry season. With an annual rainfall of $2.5 \mathrm{~m}$ or less, S. japonicum is present only in very wet regions with short dry seasons, $S$. haematobium in very dry regions with long dry seasons and, S.mansoni in regions of medium rainfall and medium-length dry seasons [57].

\subsection{El Niño}

The El Niño phenomenon, cycling with a frequency of every 2-7 years, is second only to seasonal variability as the strongest driver of weather variability in many regions of the world [58]. During El Niño, weakening of easterly trade winds causes warm equatorial Pacific water to migrate from the western to the eastern Pacific, resulting in drought in some regions of the world and flooding in others. For instance, in the East African highlands, El Niño results in excessive rainfall and in southern Africa, drought [59]. Surveillance systems need to be developed in order to identify association between climatic phenomena and locally appropriate indicators of outbreaks of parasitic disease, such as malaria.

\section{Examples of parasitic diseases affected by environmental change}

The primary types of environmental changes that affect the breeding, development, and proliferation of specific parasite species and their hosts, and their capacity to transmit disease are discussed. Illustrative examples citing malaria, leishmaniasis, cryptosporidiosis, giardiasis, trypanosomiasis, shistosomiasis, filariasis, onchocerciasis, and loiasis are briefly presented. 


\subsection{Malaria}

Malaria is ubiquitous in Africa and is flourishing in much of South America and other tropical regions. Many of the malarial parasite species and their vectors respond sharply to changes in the ecology of their habitat: deforestation, vegetation, density of human population, bodies of water and their locations and climate. For example, upsurges of malaria have been co-incident with changes in land-use and human settlement subsequent to deforestation in Africa [60,61], Asia [62], and Latin America [63,64]. Each Anopheles species occupies a unique ecological niche, and operates at a different level of vector competence. When an environment is altered, if the indigenous anophelines are not able to successfully adapt to the changed ecology, for example, to a deforested area, it will disappear, to be replaced by a different, opportunist species that moves into the vacated niche.

As the new environment undergoes the process of stabilisation, a succession of species may occupy the area. Following deforestation, the type of landuse, activity, and human settlement, and the ecological context created determines which indigenous species of mosquito are able to adapt and remain, which disappear, and which new species arrive, finding the newly formed habitat congenial to their survival and proliferation. For example, after the construction of a hydroelectric dam in Tucurui in Brazil, A. argyritarsis appeared, only to be succeeded by A. braziliensis 5 years later [64]. In Brazil, subsequent to development of mining and migration following deforestation, between 1971 and 1986, there was a 76\% increase in malaria transmitted by $A$. darlingi with $P$. falciparum increasing disproportionately to vivax [65,66]. In western Africa, deforestation and irrigation have been followed by an increase in $P$. falciparum malaria transmitted by A. gambiae in villages close to forest, $A$. funestus in the savannah, and $A$. arabiensis in urban and peri-urban areas. In sub-Saharan Africa, where malaria is hyperendemic, the highly competent malaria vector, A. gambiae, proliferates. In western Venezuela, A. nuneztovari transmits vivax malaria, but not P. falciparum malaria. Some vectors, such as A. mediopunctatus transmit simian, but not human, malaria $[64,67,68]$. Different degrees of genetic diversity in the parasite, $P$. falciparum, related to the intensity of disease (malaria) transmission have been reported from various endemic regions [12] and, between and within defined geographical areas [9-12].

A secondary effect of deforestation and initiation of crop agriculture, cattle herding, mining, and construction is the influx of new populations from other regions. Lacking familiarity in dealing with the newly deforested region's environment, resettled populations may inadvertently engage in practices leading to their becoming infected, and, in turn, becoming reservoirs of infection, rapidly leading to an increased incidence of malaria. In an interesting investigation [63], the prevalence of $P$. vivax, $P$. falciparum, and P. malariae malaria were found higher in the Waorani Indians of Ecuador living in permanent settlements with greater ecological alteration than in those maintaining their traditional nomadic lifestyle: indeed, the prevalence of $P$. falciparum antibodies in blood samples of the nomadic group was zero, suggesting that, contrary to popular belief, $P$. falciparum may not have been transmitted in the forest [60]. It has not been determined whether the absence of $P$. falciparum antibodies in the blood samples was attributable to a sparse presence of the vector or a low rate of vector infection with $P$. falciparum due to limited contact with an infected population.

The vegetation that supplants the previously forested area frequently promotes an increase in malaria prevalence. In Malaysia, during a 50-year period of repeated resowing of rubber plants, there were cyclic malaria epidemics transmitted by A. maculatus; in Trinidad, in the 1940's following deforestation, Erythrina trees, which support large numbers of bromeliads on their branches, were planted to provide shade for growing cocoa. A malaria epidemic ensued because the bromeliads, which collect water, are the preferred breeding sites of $A$. bellator. When the bromeliads were removed, malaria prevalence returned to its previous level [69].

The characteristics of bodies of water, including their vegetation, play a role in determining which mosquito species inhabits an area. In Africa, A. gambie prefers sunlit pools with turbid water with little or no emergent vegetation; A. funestus larvae prefer clear water, thriving in irrigation and hydroelectric reservoirs with their frequent changes in water level, around shorelines with vertical, emergent vegetation without organic material or salinity; A. Pharaoensis, requiring extensive vegetation cover, inhabits swamps and relatively permanent waterbodies with organic material; A. melas, the coastal areas with high salinity. Unfortunately, the wide variety of conditions under which at least one mosquito species with a malaria causing parasite can be found to thrive ensures that malaria remains endemic throughout Africa. In rural India, irrigation systems harbour A. culcifacies. In Sri Lanka, the vectors are not found in the irrigated fields or drains, but rather, in the riverine pools created by diversion of flow out of river beds, breeding primarily in shallow, stagnant surface water exposed to sunlight. A. minimus and A. balabacensis are the major malaria vectors in the hilly regions of Burma, Thailand and Indo-China. The A. balabacensis deposits its eggs in deeply shaded pools and seepages in the rain forests, in footprints, mining pits and irrigation ditches, and in excavated depressions in the open sunlight [18]. However, the $A$. minimus larvae inhabit the edges of clean, clear, gently moving streams.

Climatic conditions, temperature, altitude, humidity, rainfall, flooding, wind, and phenomena such as El Niño mitigate toward or against increase in the malaria infection. Small increases in existing low temperatures have been shown to exert a disproportionately strong effect on 
increased transmission of malaria [70-72]. New exposure can result in serious outbreaks, affecting both adults and children in areas at extremes of the temperature range, (e.g. in the highlands and lowland fringes), where the population has developed little or no immunity. Increases in temperature have been linked to malaria epidemics in Pakistan [73] and in Zimbabwe [74] where incidence and prevalence of malaria have been closely associated with altitude [75]. The Highlands of Africa, where malaria incidence is on the rise, represent an ecological zone of special concern [54]. Areas considered vulnerable to a shift in malaria transmission are those above $1000 \mathrm{~m}$ where, during the five wettest consecutive months of the year, the ratio of precipitation to potential evapotranspiration is more than 0.5 , and the minimum temperature is $15^{\circ} \mathrm{C}$ or higher [76]. Environmental monitoring in these 'transitional' zones is a priority for detecting any change in disease driven by warming trends. In a site situated at $2000 \mathrm{~m}$ in Western Kenya, malaria outbreaks have occurred when mean monthly temperature exceeds $18^{\circ} \mathrm{C}$ [77] and rainfall is greater than $150 \mathrm{~mm}$ per month. Wet and humid environments provide the breeding sites and prolong the life of malaria mosquitoes [72]. Most malaria deaths, for example, usually occur at the end of the rainy season [78]. In Rwanda, a progressive rise in temperature and heavy rainfall in 1987 and 1988 was correlated with a steep rise in malaria cases, especially at higher altitudes [79].

El Niño-affected areas have recently provided evidence that El Niño years may precipitate malaria outbreaks in different parts of the world [73,80,81]. The 1997/98 El Niño, the largest in recorded history, resulted in torrential rain in parts of East Africa and a malaria epidemic in the southwestern Uganda highlands [82]. However, El Niño is certainly not responsible for all epidemics; the extreme Ethiopian epidemics in 1953 and 1958, which resulted in thousands of deaths, did not occur in El Niño years. It is possible that, in some areas, exceptionally heavy rains may wash larvae from their breeding sites, resulting in reduced malaria [76].

Climate change may increase the risk of reintroduction of malaria unless programs to control vectors are maintained or increased [83]. In the Caucasus and Volga river basin, where there were 9 million cases of P. falciparum and P.vivax malaria each year between 1934 and 1936, [84], malaria has been eradicated. However, there is now concern, especially in the light of the recent spate of malaria in the Eastern European countries of Azerbaijan, Tajikistan, and Turkey [85], about reintroduction of malaria to these areas and the republics of the former Soviet Union because of their deteriorating health care systems.

\subsection{Leishmaniasis}

Leishmaniasis (Kala-Azar) is caused by Leishmania spp. and transmitted by phlebotomine sandflies. In some parts of Latin America, deforestation has led to an increase in leishmaniasis. The former forest has been replaced by areas of farmland, interspersed with patches of forest. With growth of the fox population, an excellent reservoir host of visceral leishmaniasis, Kala-Azar has increased and the sylvatic leishmaniasis vector sandflies have become peridomestic. In the Amazon region, human populations, accompanied by their infected dogs, have immigrated, serving to increase the prevalence of leishmaniasis [86]. Twelve years after large areas of forest in Para State in Brazil were cleared and pines and gmelina planted for a paper industry, the spiny rat, the reservoir host of cutaneous leishmaniasis parasite, had adapted to the changed environment and become infected with leishmanial parasites [87].

In mountainous coffee-growing regions of Latin America, where there are large shade trees among the coffee plants, there are phlebotomine sandflies and leishmaniasis has become a serious problem [88]. It is speculated that the sugar of the ripe coffee fruit may facilitate the development of Leishmania parasites in the vectors [89]. In the Upper Nile province in southern Sudan, an area in which KalaAzar had not been endemic, it has been suggested that an outbreak of leishmaniasis may have been attributable, in part, to a combination of the introduction of the parasite to a non-immune population by a large wave of immigrants from an area with endemic leishmaniasis and ecological changes favourable to the sandfly [90]. In southern Sudan, the sandfly circulates the Leishmania parasite among small mammals. When non-immune populations, such as construction workers, resettled populations, or refugees, enter the area, the Phlebotomus sandfly transmit the disease to them and they develop large open sores on their faces and arms. As the human population remains in the area, over the years they develop limited immunity and parasite trasmissing results in milder symptoms [57].

\subsection{Cryptosporidiosis}

Spread of waterborne zoonotic parasitic diseases, such as Cryptosporidiosis, associated with domestic livestock and readily transmitted to humans. Cryptosporidium, the parasite causing Cryptosporidiosis, is highly prevalent in ruminants, completing its life cycle within the intestine of the animal that sheds high numbers of infectious oocysts dispersed in their faeces [91].

Contamination from leaking septic tanks or agricultural runoff increases the risk for Cryptosporidium contamination of drinking water, as the oocyst is resistant to chlorine treatment during periods of heavy precipitation when there is flooding. Increases in rainfall and run-off intensity leads to heavily contaminated source waters. Concentrations of Cryptosporidium oocysts are very small $(\sim 5 \mu \mathrm{m})$, and are difficult to remove from water; a recent US study found $13 \%$ of finished treated water still contained Cryptosporidium oocysts [92], indicating passage of microorganisms from their source to treated drinking water.

In the United Kingdom [93], Montana [94], and, in 1993, in Milwaukee, Wisconsin, where the largest reported water- 
borne disease outbreak occurred, with an estimated 403000 cases of intestinal illness and 54 deaths [95]. The severity of the Milwaukee outbreak has been attributed to the heavy spring rainfall and runoff from melting snow with a subsequent turbidity load, compromising the efficiency of the drinking water treatment plant $[96,97]$. Similarly, in the Delaware River, an association was found between the amount of rainfall and the number of Cryptosporidium oocysts [98].

\subsection{Giardiasis}

Giardiasis is caused by Giardia lamblia, which is harboured by a variety of animals and crops, on its way to infecting humans. In Colorado, beaver (Castor canadensis) and muskrats (Ondatra zibethicus) serve as amplification hosts for Giardia sp., shedding the parasite cysts in their faeces, with temporal variations, throughout the year. In late spring and early fall, they contaminate surface waters downstream from their dams with Giardia sp. cysts which settle rapidly in the slow moving waters [99]. In the Rhode River, a Chesapeake Bay, Maryland subestuary, Macoma balthica clams, which harbour Giardia sp. cysts, burrow in the mud or sandy-mud substrata, feeding on the surface sediment layer. As the waters are slow moving, the waterborne Giardia sp. cysts settle to the bottom, contaminating the sediment [22]. An example of the introduction of a parasitic disease to an animal species by a human population occurred in Uganda. The Ugandan mountain gorilla population, Gorilla gorilla beringei, had become habituated to humans through growing ecotourism and conservation activities. The prevalence of Giardia sp. infections in the gorillas habituated to humans was considerably greater than that of the nonhabituated gorillas [23].

In Marrakech, where raw sewage has been used to irrigate a variety of vegetable crops, potatoes irrigated with raw waste water were contaminated with Giardia sp. cysts [100].

\subsection{Trypanosomiasis}

Trypanosomiasis is caused by Trypanosoma spp.: $T$ bruci varieties gamiense and rhodesiense cause Gambian and Rhodesian trypanosomiasis (African sleeping sickness); in cattle, called Ngana in parts of Africa) and T. cruzi causes South American trypanosomiasis (Chagas' disease). The African forms are transmitted by the tsetse fly (Glossina) and Chagas' disease by contamination of the Triatoma bug with infected insect faeces and by transfusion of contaminated blood. In Africa, it is not economically feasible to raise cattle on large areas of land due to high prevalence of tsetse flies, so cattle ranching is often confined to dry areas where tsetse flies cannot survive. The overstocking results in poor quality cattle and causes land degradation. When there is deforestation, these effects are exacerbated if the forest is replaced by tall crops such as cocoa, coffee, oil palms and mangoes, which provide comfortable habitats for tsetse colonisation. Human populations, who come to work the land and tend the herds, are vulnerable to infection. As the tsetse fly requires the protection of vegetation or forests, in the African Sahel zone they inhabit the river banks, moving into drier areas during the rainy seasons and returning to the forests during dry seasons [57].

In Central and South America, domestic and peridomestic animals such as dogs, cats, armadillos, opossums, and rodents serve as host reservoirs for Triatoma. In the Salta area of Argentina, good livestock management, compatible with the environment, has restored the original productivity of the ecosystem. Areas were enclosed so that natural vegetation could recover, in some instances leading to afforestation, and cattle grazing was conducted under a controlled, managed program [101].

It has been predicted that the Brazilian Amazon is at risk for Chagas disease becoming endemic due to the confluence of a number of factors-uncontrolled deforestation and colonisation, altering the ecological balance between reservoir hosts and wild vectors, adaptation of reservoir hosts and wild vectors to peripheral and living areas as the sole feeding source, and migration of infected human population and their domestic reservoir hosts [102]

\subsection{Trematode}

\subsubsection{Shistosomiasis (Bilharzia)}

Shistosomiasis (Bilharzia) is caused by the Shistosoma blood flukes, primarily S. haematobium, S. mansoni, and $S$. japonicum, and in the Mekong River area of IndoChina, S. mekongi which closely resembles $S$. japonicum. The larvae dwell in their intermediate host, the snail, for about 1 month, before escaping into water, seeking a human host. The abundance of the parasite is in direct proportion to that of the snail population. Snails egg laying is dependent on the type of vegetation in the habitat, not only seasonal rain variation and changes in water temperature and flow, but also by the abundance of snails, and hence that of the parasite changes in the type and quantity of vegetation. Shistosoma species vary considerably in their preferences for amount of rainfall, length of the rainy and dry seasons, and interval between rainy and dry seasons, as described above (under 'Temperature and Rainfall').

In the Nile Delta below Cairo and in the Sudan, the prevalence of bilharzia parallels the degree of irrigation intensity, as the snail is pumped along with the water [57]. With the construction of the Roseires and Aswan Dams in Egypt, year-round irrigation became possible and snail populations swelled. The intestinal form of bilharzia has prevailed throughout the Gezira irrigation system since 1970, when a storage dam was added to the original Gezira irrigation system of the central Sudan [103].

In Iran, construction of an improved irrigation system and a new canal system resulted in an upsurge in the prevalence of bilharzia, especially among those working and living within the immediate area [57]. 
In China, subsequent to the construction of the Three Gorges high dam on the Yangtze River, the snail distribution and annual prevalence of human schistosomiasis varied significantly in accordance with water levels in the Yangzte River, in a direct association with density of the snails, the water table, annual rainfall, yearly evaporation and ground altitude [104].

\subsection{Tissue Nematodes}

\subsubsection{Filariasis}

Filariasis is most commonly caused in humans by the Wuchereria bancrofti parasite, transmitted by Aedes, Culex and Anopheles mosquitoes. In the Orient, rice cultivation and flooding are associated with increased prevalence of filariasis [57], and in the Nile delta, changes in soil moisture have preceded changes in prevalence of Bancroftian filariasis [105]. In India, standing water, polluted by faeces of domestic animals, provide breeding grounds, and wandering pigs and cows destroy the banks of unlined drains, creating shallow larval habitats [106].

\subsubsection{Onchocerciasis (river blindness)}

Onchocerciasis is caused by the parasite, Onchocerca volvulus, and transmitted by the bite of the blackfly, Spp. Simuliidae. In each of the areas in which it occurs, West, Central and East Africa, Ecuador, Guatemala and Mexico, it is transmitted by a different species of Simuliidae. In Africa, rapids or white water on spillways and water control structures provide breeding sites for the blackfly. In Nigeria, river blindness is most common along the main river valleys. In the Plateau State in Nigeria, the vectors breed during the wet season and peak biting density occurs at the height of the rainy season, with more infective parasites at the beginning and end of rain [107].

\subsubsection{Loiasis}

Loiasis (calabar swellings), is caused by Loa loa and transmitted to humans by the bite of the Chrysops fly. In Central and West Africa, the vector's natural habitat is dense forest and the forest edge with the forest swamp serving as the breeding ground. Although deforestation reduces its prevalence, it has also adapted to rubber plantations [108].

\section{Coping with the future}

The continued disturbance of natural ecosystems by destructive changes in landuse, especially deforestation, and poor husbanding of natural resources has modified the distribution and behaviour of parasites, their hosts and vectors. The examples cited in this brief review demonstrate the close relationships among landuse, climate variability and human disease.

Improved surveillance and monitoring is needed so as to detect changes resulting from global climate and ecological change, both for identification of immediately required action and to serve as the basis for developing predictive models. Such models can serve as effective aids in developing strategies and mechanisms for minimising parasitic disease consequent to expected changes in the environment; they can provide insight into associations among ecological factors, entomological, genetic and behavioural characteristics of vectors and parasites, and human behaviour that are associated with disease transmission.

Further investigation and exploration are needed in order to gain a better understanding and control of these forces so as to prevent increasing damage to our ecosystem and reverse the rising morbidity and mortality from parasitic disease. Multidisciplinary co-operation among workers in public health, ecology, and the social and physical sciences holds out the best hope for developing comprehensive risk assessment to aid local, national and international governments and decision makers.

\section{Acknowledgements}

Funding for A.Y. Vittor and partial funding for J.A. Patz was provided through a grant from the New York Community Trust.

\section{References}

[1] Service MW. Agricultural development and arthropod-borne diseases: a review. Rev Saude Publica 1991;25:165-78.

[2] Giglioli G. Ecological change as a factor in renewed malaria transmission in an eradicated area: a localized outbreak of A. aquasalis transmitted on the Demerara River estuary, British Guinea, in the fifteenth year of A. darlingi and malaria eradication. Bull World Health Org 1963;29:131-45.

[3] Tyssul Jones TW. Deforestation and epidemic malaria in the wet and intermediate zones of Ceylon. Ind J Malariolog 1951;5(1):135-61.

[4] Sioli H. Amazonia: fundamentos da ecologia da maior regiao de florestas tropicais. Petropolis: Vozes Ltda, 1985.

[5] Marques AC. Human migration and the spread of malaria in Brazil. Parasitol Today 1987;3:166-70.

[6] Encarnacion F. El bosque y las formaciones vegetales en la llanura amazonica del Peru. Alma Mater 1993;6:95-114.

[7] Southgate VR. Shistosomiasis in the Senegal River Basin: before and after the construction of dams at Diama Senegal and Manantali, Mali and future prospects. J Helminthol 1997;71(2):125-32.

[8] Conn JE, Freitas-Sibajev MGR, Luz SLB, Momen H. Molecular population genetics of the primary malaria vector Anopheles darlingi using mtDNA. J Am Mosquito Contrl Assoc 1999;15:468-74.

[9] Babiker HA, Walliker D. Current views on the population structure of Plasmodium falciparum: implications for control. Parasitol Today 1997;13:262-7.

[10] Paul REL, Packer MJ, Walmsley M. Mating patterns in malaria parasite populations of Papua New Guinea. Science 1995;269:1709.

[11] Paul REL, Hackford I, Brockman A, et al. Transmission intensity and Plasmodium falciparum diversity on the northwestern border of Thailand. Am J Trop Med Hyg 1998;58:195-203.

[12] Babiker HA, Lines J, Hill WG, Walliker D. Population structure of Plasmodium falciparum in villages with different malaria endemicity in East Africa. Am J Trop Med Hyg 1997;56(1):41-147. 
[13] Kapel CM. Trichinella in Arctic, subarctic and temperate regions: Greenland, the Scandinavian countries and the Baltic States. Southeast Asian J Trop Med Public Health 1997;28(Suppl 1):14-19.

[14] Graczyk TK. Immunobiology of trematodes in vertebrate hosts. In: Fried B, Graczyk TK, editors. Advances in Trematode Biology. Boca Raton, FL: CRC Press, 1997. pp. 383-404.

[15] Graczyk TK, Fried B. Echniostomiasis: a common but forgotten food-borne disease. Am J Trop Med Hyg 1998;58:501-4.

[16] Graczyk TK, Fried B. Development of Fasciola hepatica in the intermediate host. In: Dalton JP, editor. Fasciolosis. New York: CAB International, 1998. pp. 31-46.

[17] McCrindle CM, Hay IT, Odendaal JS, Calitz EM. An investigation of the relative morbidity of zoonoses in paediatric patients admitted to G.A. Rankuwa Hospital. J South African Vet Assoc 1996;67:151-4.

[18] World Health Organisation. Manual on environmental management for mosquito control. Offset Publication Number 66. Geneva: World Health Organisation, 1982.

[19] Geoecologia y desarollo Amazonico: estudio integrado en la zona de Iquitos. In: Kalliola R, Flores Paitan S, editors. Peru. Sulkava: Finnreklama Oy, 1998.

[20] Fowler ME. Husbandry and disease of camelids. Rev Sci Technol 1996;15:155-69.

[21] Hunter DL. Tuberculosis in free-ranging, semi-ranging and captive cervids. Rev Sci Technol 1996;15:171-81.

[22] Graczyk TK, Lowenstine LJ, Cranfield MR. Capillaria hepatica (Nematoda) infections in human-habituated Mountain gorillas (Gorilla gorilla beringei) of the Parc National de Volcans Rwanda. J Parasitol 1999;85(6):1168-70.

[23] Nizeyi JB, Mwebe R, Nanteza A, Cranfield MR, Kalema GRNN, Graczyk TK. Cryptosporidium sp. and Giardia sp. infections in mountain gorillas (Gorilla gorilla beringei) of the Bwindi Impenetrable National Park, Uganda. J Parasitol 1999;85(6):1084-8.

[24] Cambre RC, Buick WW. Special challenges of maintaining wild animals in captivity in North America. Rev Sci Technol 1996;15:251-66.

[25] Schultz DJ, Hough IJ, Boardman W. Special challenge of maintaining wild animals in captivity in Australia and New Zealand. Rev Sci Technol 1996;15:289-308.

[26] Williams ES, Thorne ET. Infectious and parasitic diseases of captive carnivores, with special emphasis on the black-footed ferret (Mustellla nigripes). Rev Sci Technol 1996;15:91-114.

[27] Hannah HW. Zoos and veterinarians; some legal issues. J Vet Med Assoc 1998;213:1559-60.

[28] Michalak K, Austin C, Diesel S, Bacon MJ, Zimmerman P, Maslow JN. Mycobacterium tuberculosis infection as a zoonotic disease: transmission between humans and elephants. Emerg Infect Dis 1998;4(2):283-7.

[29] Tully TN, Shane SM. Husbandry practices as related to infectious and parasitic diseases of farmed ratites. Rev Sci Techno 1996;15:73-89.

[30] Gavazzi G, Prigent D, Baudet JM, Banoita S, Daoud W. Epidemiologic aspects of 42 cases of human brucellosis in the Republic of Djibouti. Med Tropicale 1997;57:365-8.

[31] Pedersen K, Dalsgaard I, Larsen JL. Vibrio damsela associated with diseased fish in Denmark. Appl Environ Microbiol 1997;63(9):3711-5.

[32] Wilson ML, Bretsky PM, Cooper GH, Egberson SH, Van Kruiningen HJ, Cartter ML. Emergence of raccoon rabies on Connecticut 1991-1994: spatial and temporal characteristics of animal infection and human contact. Am J Trop Med Hyg 1997;57(4):457-63.

[33] Weiss RA, Wrangham RW. From pan to pandemic. Nature 1999;397:385-6.

[34] Wolfe ND, Eitel MN, Gockowski J, et al. Deforestation hunting and the ecology of microbial emergence. Global Change \& Human Health 2000;1(1):10-25.

[35] Washino RK, Wood BL. Application of remote sensing to arthropod vector surveillance and control. Am J Trop Med Hyg 1994;50(6 Suppl):134-44.

[36] Schimel D, Alves D, Enting I, et al. Radiative forcing of climate change. In: Houghton JT, Meira-Filho LG, Callander BA, Harris N, Kattenberg A, Maskell K, et al., editors. Climate change 1995. The science of climate change. Cambridge: Cambridge University Press, 1996. pp. 65-131.

[37] Chappellaz J, Barnola JM, Raynaud D, Korotkevich YS, Lorius C. Ice-core record of atmospheric methane over the past 160000 years. Nature 1990;345:127-31.

[38] World Meteorological Organisation/United Nations Environment Programme. Scientific assessment of ozone depletion: 1994. Global Ozone Research and Monitoring Project Report No. 25. Geneva: World Meteorological Organisation, 1995.

[39] Karl TR, Knight RW. The 1995 Chicago heat wave: how likely is a recurrence? Bull Am Meteorol Soc 1997;78(6):1107-19.

[40] Kattenberg A, Giorgi F, Grassl H, et al. Climate models projections of future climate. In: Houghton JT, Meira-Filho LG, Callander BA, Harris N, Kattenberg A, Maskell K, et al., editors. Climate change 1995. The science of climate change. Cambridge: Cambridge University Press, 1996. pp. 285-357.

[41] Nicholls N, Gruza GV, Jouzel J, Karl TR, Ogallo LA, Parker DE. Observed climate variability and change. In: Houghton JT, MeiraFilho LG, Callander BA, Harris N, Kattenberg A, Maskell K, editors. Climate change 1995. The science of climate change. Cambridge: Cambridge University Press, 1996. pp. 133-92.

[42] Karl TR, Steurer PM. Increased cloudiness in the United States during the first half of the twentieth century: fact or fiction? Geophys Res Lett 1990;17:1925-8.

[43] Groisman PY, Easterling DR. Variability and trends of precipitation and snowfall over the United States and Canada. J Climate 1994;7:184-205.

[44] Karl TR, Knight RW, Plummer N. Trends in high-frequency climate variability in the twentieth century. Nature 1995;377(6546):217-20.

[45] Karl TR, Knight RW, Easterling DR, Quayle RG. Indices of climate change for the United States. B Am Meteor Soc 1996;77:279-303.

[46] Karl TR, Knight RW. Secular trends of precipitation amount, frequency, and intensity in the USA. Bull Amer Meteor Soc 1998;79:231-41.

[47] Shindell DT, Rind D, Lonergan P. Increased polar stratospheric ozone losses and delayed eventual recovery owing to increasing greenhouse-gas concentrations. Nature 1998;392:589-92.

[48] Patz JA, Engelberg D, Last J. The effects of changing weather on public health. Annual Rev Public Health 2000;289:1763-65.

[49] Kirk-Davidoff DB, Hintsa EJ, Anderson NG, Keith DW. The effect of climate change on ozone depletion through changes in stratospheric water vapour. Nature 1999;402:399-401.

[50] Martens P. Health and climate change, in Earthscan. London, 1998.

[51] Sutherst RW. Arthropods as disease vectors in a changing environment, Environmental Change and Human Health. Chichester: Wiley, 1993. pp. 124-45.

[52] Rogers DJ, Randolph SE. The global spread of malaria in a future, warmer world. Science 2000;289:1763-65.

[53] Barry RG. Mountain weather and climate. London: Routledge, 1992.

[54] Lindsay SW, Martens WJM. Malaria in the African highlands: past, present and future. Bull World Health Org 1998;76(1):33-45.

[55] Perciasepe R. Combined sewer overflows: where are we four years after adoption of the CSO control policy? Washington (DC): EPA Office of Wastewater Management, 1998

[56] Rose JB, Simonds J. King County water quality assessment: assessment of public health impacts associated with pathogens and combined sewer overflows. Seattle, WA: Water and Land Resources Division, Department of Natural Resources, 1998.

[57] Jobin W. Ecological design and health impacts of large dams, canals, and irrigation systems. London: E\&F.N. Spon, 1999.

[58] Ropelewski CF, Halpert MS. Global and regional scale precipitation 
patterns associated with the El Niño southern oscillation. Monthly Weather Rev 1987;115:1606-26.

[59] Ropelewski CF, Halpert MS. Global and regional scale precipitation patterns associated with the El Niño southern oscillation Monthly Weather Rev 1987;111:517-28.

[60] Coluzzi M, Sabatini A, Petrarca V, Di Deco MA. Chromosomal differentiation and adaptation to human environments in the Anopheles gambiaecomplex. Trans $\mathrm{R}$ Soc Trop Med Hyg 1979;73(5):483-97.

[61] Coluzzi M, Petrarca V. Di Deco. M.A. Chromosomal inversion intergradation and incipient speciation in Anopheles gambiae. Bull Zool 1985;52:45-63.

[62] Bunnag T, Sornmani S, Phinichpongse S, Harinasuta C. Surveillance of water-borne parasitic infections and studies on the impact of ecological changes on vector mosquitoes of malaria after dam construction, 21st SEAMEO-TROPMED Seminar: environmental impact on human health in southeast and east Asia. Tokyo: Tsukuba, 1979.

[63] Kaplan JE, Larrick JW, Yost J, et al. Infectious disease patterns in the Waorani, an isolated Amerindian population. Am J Trop Med Hyg 1980;29(2):298-312.

[64] Tadei WP, Dutary Thatcher B, Santos JMM, et al. Ecological observations on Anopheline vectors of malaria in the Brazilian Amazon. Am J Trop Med Hyg 1998;59(2):325-35.

[65] Sawyer D. Frontier malaria in the amazon region of brazil: types of malaria situations and some implications for control. Presented to the symposio sobre a malaria. Sao Paulo 1988.

[66] Pan American Health Organization. Status of malaria programs in the Americas. Report CD33/INF2. Washington, DC, 1988 (mimeographed document).

[67 Rubio-Palis Y. Variation of the vectorial capacity of some anophelines in western Venezuela. Am J Trop Med Hyg 1994;50(4):420-4.

[68] Lourenco-de-Oliveira R, Da Gama AE, Arle M, et al. Anopheline Species, some of their habits and relation to malaria in endemic areas of Rondonia state, Amazon region of Brazil. Mem Inst Oswaldo Cruz 1989;84(4):501-14.

[69] Downs WG, Pittendrigh CS. Bromeliade malaria in Trinidad. British West Indies. Am J Trop Med Hyg 1946;26:47-66.

[70] Bradley DJ. Human tropical diseases in a changing environment. In: Environmental change in human health. Chichester: Wiley, 1993. pp. 146-70.

[71] Martens WJM, Rotmans J, Niessen LW. Climate change and malaria risk: an integrated modelling approach. Bilthoven, The Netherlands: Rijksinstituut voor Volksgezondheid en Milieuhygiene, 1994.

[72] Lindsay SW, Birley MH. Climate change and malaria transmission. Ann Trop Med Parasitol 1996;90:573-88.

[73] Bouma MJ, van der Kaay HJ. Epidemic malaria in India and the El Niño southern oscillation. Lancet 1994;344:1638-9.

[74] Freeman T, Bradley M. Temperature is predictive of severe malaria years in Zimbabwe. Trans R Soc Trop Med Hyg 1996;90:232.

[75] Taylor P, Mutambu SL. A review of the malaria situation in Zimbabwe with special reference to the period 1972-1981. Trans R Soc Trop Med Hyg 1986;80:12-19.

[76] Patz JA, Lindsay SW. New challenges, new tools: the impact of climate change on infectious diseases. Curr Opin Microbiol 1999;2:445-51.

[77] Malakooti MA, Biomndo K, Shanks DG. Re-emergence of epidemic malaria in the highlands of western Kenya. Emerg Infect Dis 1998;4:671-6.

[78] Greenwood BM, Pickering H. A malaria control trial using insecticide-treated bed nets and targeted chemoprophylaxis in a rural area of The Gambia West Africa. 1. A review of the epidemiology and control of malaria in The Gambia, West Africa. Trans R Soc Trop Med Hyg 1993;87(Suppl 2):3-11.

[79] Loevinsohn M. Climatic warming and increased malaria incidence in Rwanda. Lancet 1994;343:714-8.

[80] Bouma MJ, van der Kaay HJ. The El Niño southern oscillation and the historic malaria epidemics on the Indian subcontinent and Sri Lanka: an early warning system for future epidemics? Trop Med Int Health 1996;1:86-96.

[81] Bouma MJ, Poveda G, Rojas W, et al. Predicting high-risk years for malaria in Columbia using parameters of El Niño southern oscillation. Trop Med Int Health 1997;2(12):1122-7.

[82] Kilian AHD, Langi P, Talisuna A, Kabagambe G. Rainfall pattern El Niño and malaria in Uganda. Trans $\mathrm{R}$ Soc Trop Med Hyg 1999;93:22-23.

[83] World Health Organisation. Monograph on water resources and human health in Europe. Rome: WHO, European Centre for Environment and Health/European Environment Agency, 1999.

[84] Bruce-Chwatt LJ. History of malaria from prehistory to eradication. In: Wernsdorfer WH, McGregor I, editors. Malaria: principles and practise of malariology. Edinburgh: Churchill Livingstone, 1988. pp. $1-59$.

[85] Pitt S, Pearcy BE, Stevens RH, Sharipov A, Satarov K, Banatvala N. War in Tajikistan and re-emergence of Plasmodium falciparum. Lancet 1998;352:1279.

[86] Lainson R. Demographic changes and their influence on the epidemiology of the American leishmaniasis. In: Service MW, editor. Demography and vector-borne diseases. Boca Raton, FL: CRC Press, 1989. p. 85.

[87] Ready PD, Lainson R, Shaw JJ. Leishmaniasis in Brazil: XX Prevalence of 'enzootic rodent leishmaniasis' (Leishmania mexicana amazonensis), and apparent absence of 'pian bois' (Le. braziliensis guyanensis), in plantations of introduced tree species and in other non-climax forests in eastern Amazonia. Trans R Soc Trop Med Hyg 1983;77(6):775-85.

[88] Warburg A, Montoya-Lerma J, Jaramillo C, Cruz-Ruiz AL, Ostrovska K. Leishmaniasis vector potential Lutzomyiaspp. in Colombian coffee plantation. Med Vet Ent 1990;5:9-16.

[89] Scorza JV, Castillo L, Rezzano S, Marquez M, Marquez C. El papel $\mathrm{d}$ cafeto en la endemicidad de la leishmaniasis cutanea en Venezuela. Bol Direcc Malar Saneam amb 1985;25:82-88.

[90] Zijlstra EE, Ali MA, el-Hassan AM, et al. Kala-azar in displaced people from southern Sudan: epidemiological, clinical and therapeutic findings. Trans R Soc Trop Med Hyg 1991;85(3):365-9.

[91] Fayer R, Speer CA, Dubey JP. The general biology of Cryptosporidium. In: Fayer R, editor. Cryptosporidium and Cryptosporidiosis. Boca Raton, FL: CRC Press, 1997. pp. 1-42.

[92] LeChevallier MS, Norton WD. Giardia and Cryptosporidium in raw and finished water. J Am Water Works Assoc 1995;87(9):54-68.

[93] Anonymous. Cryptosporidium in water supplies. London: Department of the Environment, Department of Health 1990.

[94] Weniger BG, Blaser MJ, Gedrose J, Lippy EC, Juranek DD. An outbreak of waterborne giardiasis associated with heavy water runoff due to warm weather and volcanic ashfall. Am J Public Health 1983;73(8):868-72.

[95] Hoxie NJ, Davis JP, Vergeront JM, Nashold RD, Blair KA. Cryptosporidiosis-associated mortality following a massive waterborne outbreak in Milwaukee Wisconsin. Am J Public Health 1997;87(12):2032-5.

[96] Mac Kenzie WR, Hoxie NJ, Proctor ME, et al. A massive outbreak in Milwaukee of cryptosporidium infection transmitted through the public water supply. N Engl J Med 1994;21:1 21;331(3):161-7.

[97] Kramer MH, Herwaldt BL, Craun GF, Calderon RL, Juranek DD. Surveillance for waterborne-disease outbreaks-United States 19931994. Mor Mortal Wkly Rep CDC Surveill Summ 1996;45(1):1-33.

[98] Alterholt TB, LeChevallier MW, Norton WD, Rosen JS. Effect of rainfall on giardia and crypto. $\mathrm{J}$ Am Water Works Assoc 1998;90(9):66-80.

[99] Monzingo Jr. DL, Hibler CP. Prevalence of Giardia sp. in a beaver colony and the resulting environmental contamination. J Wildl Dis 1987;23(4):576-85.

[100] Amahmid O, Asmama S, Bouhoum K. The effect of waste water reuse in irrigation on the contamination level of food crops by Giar- 
dia cysts and Ascaris eggs. Int J Food Microbiol 1999;49(1-2):1926.

[101] Bucher EH, Toledo C. Livestock management and disease vector control 1990; PEEM/WP/10/90.6 - mimeographed; Solbrig, O. Destruccion o transformacion de paisaje tropical sudamericano? Interciencia 1998;13:79-82.

[102] Coura JR, Junqueira AC, Giordano CM, Funatsu RK. Chagas; disease in the Brazilian Amazon. I-A short review. Revista do Instituto de Medicina Tropical de Sao Paulo 1994(4):363-8.

[103] Amin M, Fenwick A, Teesdale C, McLaren M. The assessment of a 3 year snail control programme in the Gezira irrigated area Sudan. Ann Trop Med Hygiene Parasitol 1982;76:557-80.

[104] Xu XJ, Yang XX, Dai YH, Yu GY, Chen LY, Su ZM. Impact of environmental change and schistosomiasis transmission in the middle reaches of the Yangtze River following the Three Gorges construction project. Southeast Asian J Trop Med Public Health 1999;30(3):549-55.
[105] Thompson DF, Malone JB, Harb M, et al. Bancroftian filariasis distribution in the southern Nile delta: correlation with diurnal temperature differences from satellite imagery. Emerg Infect Dis 1996;3(3):234-5.

[106] Rajagopalan PK, Das PK, Paniker KN, Reuben R, Rao DR, Self LS, Lines JD. Environmental and water management for mosquito control. In: Curtis CF, editor. Appropriate technology in vector control. Boca Raton, FL: CRC Press, 1990. pp. 121-38.

[107] Nwoke BE, Onwuliri CO, Ufomadu GO. Onchocerciasis in Plateau State Nigeria: ecological background, local disease perception \& treatment; and vector/parasite dynamics. J Hyg Epidemol Microbiol Immunol 1992;36(2):153-60.

[108] Duke BOL. Behavioral aspects of the life cycle of loa. In: Canning EU, Wright CA, editors. Behavioural aspects of parasitic transmission. Supplement No. 1 Zoological Journal of the Linnean Society 51. London: Academic Press, 1972. pp. 97-107. 